Publication No. FHWA-RD-95-116

December 1995

\title{
Automated Measurement of Aggregate Indices of Shape
}

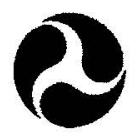

U.S. Department of Transportation

\section{Federal Highway Administration}

Research and Development

Turner-Fairbank Highway Research Center 6300 Georgetown Pike

McLean, Virginia 22101-2296 


\title{
FOREWORD
}

This report presents research results of a 1993 grant study in the Discretionary Grants to Support Advanced Highway Research program.

Aggregate angularity is believed a critical factor in improving pavement resistance to rutting. However, the lack of a direct technique to measure aggregate angularity has prevented detailed studies of the relationship between aggregate angularity and the pavement performance. This study deals with the development of an automated system for measuring aggregate angularity. Shape indices were developed from basic linear measurements and Hough Transform technique. Quantifying aggregate shape by shape indices will enable the study of mechanisms of pavement deformation.

Two copies of this report are being distributed to each of the Federal Highway Administration regional and division offices. The division office should send one copy to the State highway agency.

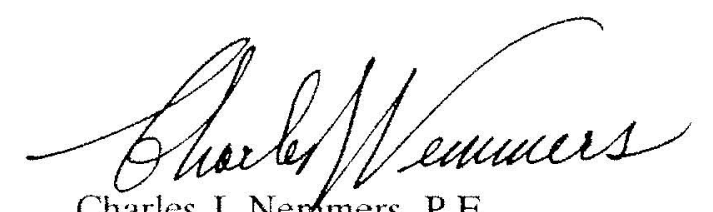

Charles J. Newmers, P.E.

Director, Office of Engineering Research \& Development

\begin{abstract}
NOTICE
This document is disseminated under the sponsorship of the Department of Transportation in the interest of information exchange. The United States Government assumes no liability for its contents or use thereof. This report does not constitute a standard, specification, or regulation.

The contents of this report reflect the views of the authors, who are responsible for the facts and accuracy of the data presented herein. The contents do not necessarily reflect the official policy of the Department of Transportation.

The United States Government does not endorse products or manufacturers. Trade and manufacturers' names appear in this report only because they are considered essential to the object of the document.
\end{abstract}




\begin{tabular}{|c|c|c|}
\hline $\begin{array}{l}\text { 1. Report No. } \\
\text { FHWA-RD-95-116 }\end{array}$ & 2. Government Accession No. & 3. Recipient's Catalog No. \\
\hline \multirow{2}{*}{\multicolumn{2}{|c|}{$\begin{array}{l}\text { 4. Title and Subtitle } \\
\text { AUTOMATED MEASUREMENT OF AGGREGATE } \\
\text { INDICES OF SHAPE }\end{array}$}} & $\begin{array}{l}\text { 5. Report Date } \\
\text { December } 1995\end{array}$ \\
\hline & & 6. Performing Organization Code \\
\hline \multicolumn{2}{|c|}{$\begin{array}{l}\text { 7. Author(s) } \\
\text { J. D. Wilson, L. D. Klotz, C. Nagaraj }\end{array}$} & 8. Performing Organization Report No. \\
\hline \multirow{3}{*}{\multicolumn{2}{|c|}{$\begin{array}{l}\text { 9. Pertorming Organization Name and Address } \\
\text { University of Arkansas at Little Rock } \\
\text { 2801 South University } \\
\text { Little Rock, AR } 72203\end{array}$}} & $\begin{array}{l}\text { 10. Work Unit No. (TRAIS) } \\
3 \mathrm{H} 2 \mathrm{~d}-3027\end{array}$ \\
\hline & & $\begin{array}{l}\text { 11. Contract or Grant No. } \\
\text { DTFH61-93-X-00034 }\end{array}$ \\
\hline \multirow{3}{*}{\multicolumn{2}{|c|}{$\begin{array}{l}\text { 12. Sponsoring Agency Name and Address } \\
\text { Office of Engineering and Highway Operations R\&D } \\
\text { Federal Highway Administration } \\
\text { 6300 Georgetown Pike } \\
\text { McLean, VA 22101-2296 }\end{array}$}} & 13. Type of Report and Period Covered \\
\hline & & $\begin{array}{l}\text { Final Report } \\
\text { June } 1993 \text { - September } 1994\end{array}$ \\
\hline & & 14. Sponsoring Agency Code \\
\hline
\end{tabular}

15. Supplementary Notes

Contracting Officer's Technical Representative - Dr. Dah-Cheng Woo,

HNR-2

16. Abstract

Aggregate angularity is a significant factor in determining pavement resistance to rutting. Determination of aggregate angularity by direct means allows a more meaningful study of the mechanisms of pavement deformation. However, direct techniques have not been developed sufficiently to allow a more advanced study of angularity effects on pavement. Utilizing modern digital imaging hardware and image analysis techniques, this project produced an automated system for measuring aggregate angularity. Combining high resolution video, image capture hardware, sample transport, and computerized analysis, an instrument was constructed and used to compare various aggregate samples. Differentiation of known good quality aggregate from poorer grades was possible. Shape indices were developed from basic linear measurements, and the Hough Transform technique. These indices appear to have value in quantifying aggregate shape, and enable the study of mechanisms of pavement deformation, and possibly the prediction of pavement longevity.

\section{TECHNICAL REFERENCE CENTER \\ Turner-Fairbank Hwy Res Cntr \\ FHWA, Room A200 \\ 6300 Georgetown Pike \\ McLean, VA 22201}

\section{Key Words}

Aggregate, natural sands, angularity, angular, roundness, video, pavement, shape, Hough

Transform, digital imaging.
18. Distribution Statement

No Restrictions. This document is available to the public from the National Technical Information Service, Springfield, Virginia 22151

\begin{tabular}{|l|l|c|l|}
\hline $\begin{array}{l}\text { 19. Security Classif. (of this report) } \\
\text { Unclassified }\end{array}$ & $\begin{array}{l}\text { 20. Security Classit. (of this page) } \\
\text { Unclassified }\end{array}$ & $\begin{array}{c}\text { 21. No. of Pages } \\
29\end{array}$ & 22. Price \\
\hline
\end{tabular}

Form DOTF 1700.7

(8-72)

Reproduction of completed page authorized 


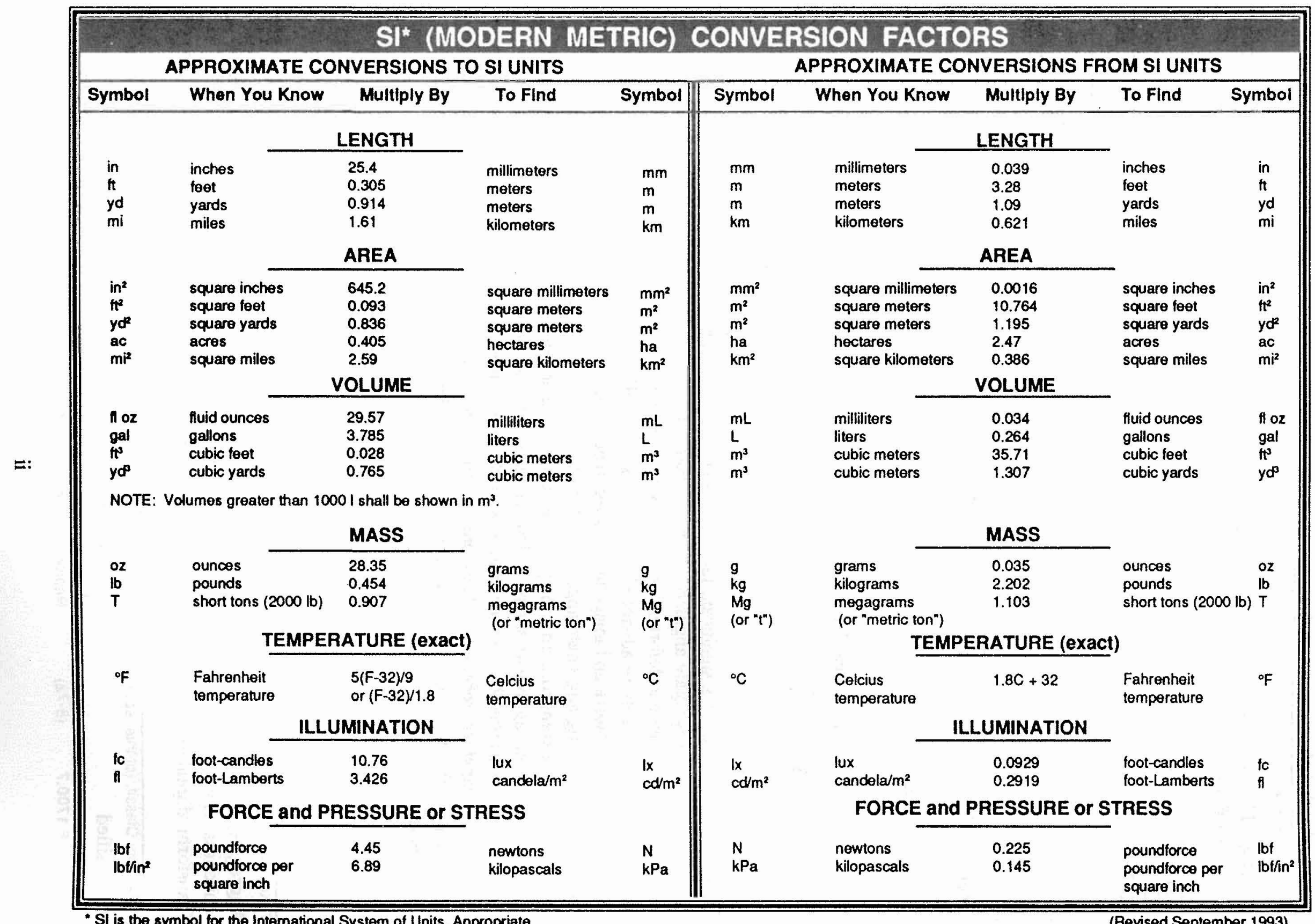

"SI is the symbol tor the International System of Units. Appropriate

(Revised September 1993) 
TABLE OF CONTENTS

Section

$\underline{\text { Page }}$

CHAPTER 1: INTRODUCTION AND OBJECTIVES ..................................... 1

1. Problem ................................................................................ 1

2. Objectives.............................................................................................. 2

CHAPTER 2: INSTRUMENTATION ...........................................................

1. Video System .................................................................................. 3

2. Sample Transport..................................................................................... 3

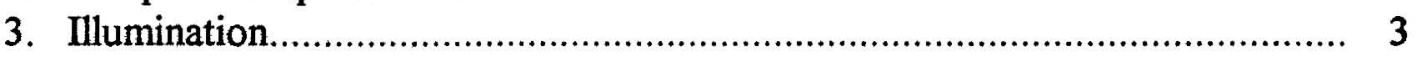

4. Data Capture Software ............................................................................. 5

5. Calibration Procedure ………………....................................................... 6

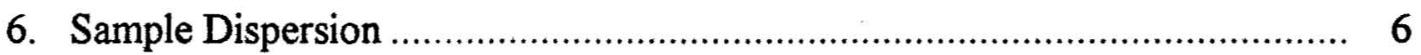

CHAPTER 3: FEATURE EXTRACTION ……........................................... 7

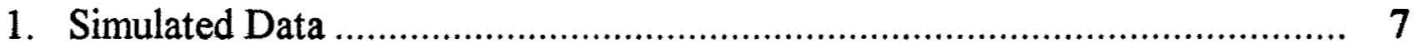

2. Basic Measurements .......................................................................... 7

a. Area and Perimeter............................................................................... 7

b. Length Measurements and Aspect Ratio ................................................. 8

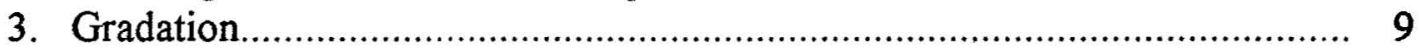

4. CAPP Index and EAPP Index …………………................................. 9

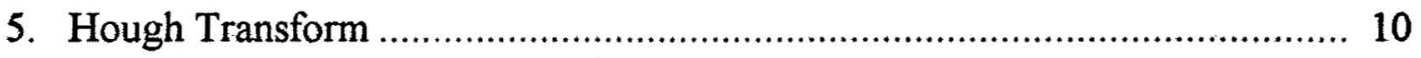

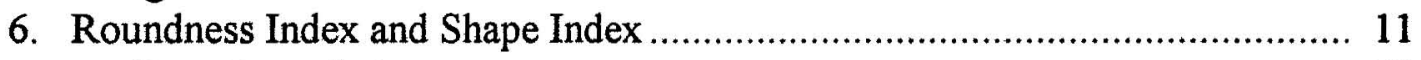

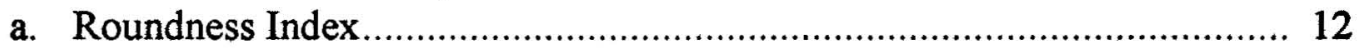

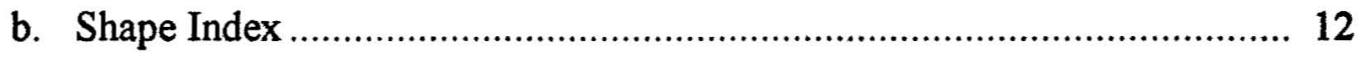

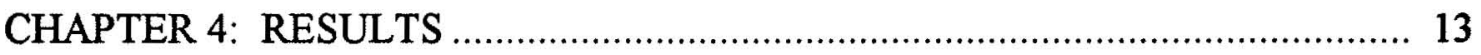

1. Measurement of Basic Parameters........................................................... 13

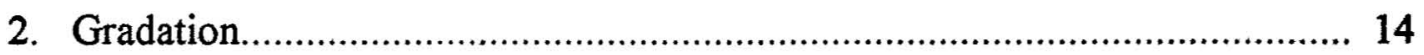

3. CAPP, EAPP, Roundness, and Shape Indices............................................. 14

CHAPTER 5: CONCLUSIONS AND RECOMMENDATIONS ........................... 19

1. Accuracy of Basic Measurements........................................................ 19

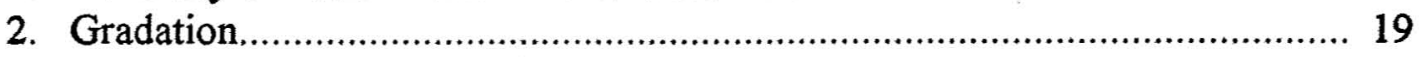

3. CAPP Index and EAPP Index .......................................................... 19

4. Roundness Index and Shape Index ........................................................ 20

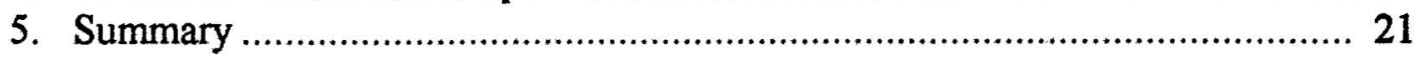

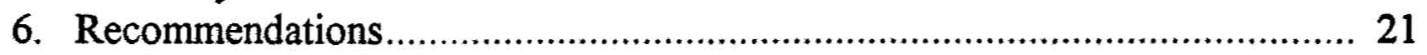

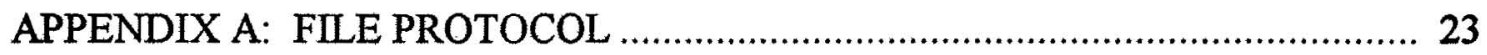

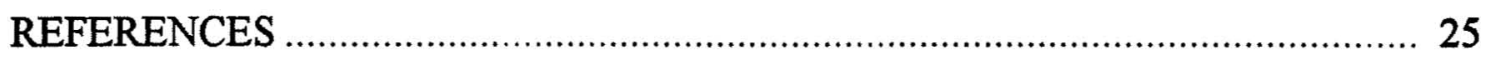




\section{LIST OF FIGURES}

Figure $\quad$ Page

1. A view of the $X Y$ table, Delrin diffuser, and Lexan sample plate ...................... 4

2. a) Original image. b) Object discrimination. c) Edge trace ......................... 5

3. Definition of width, length, and maximum length. Segment bc is the width, segment $a b$ is the length, and segment ac is the maximum length ................... 8

4. Hough transform example. All points that lie on or close to line segment ab will be counted and placed into the Hough transform cell found at coordinates $r$ and $\theta$

5. The cumulative volume distribution of Ottowa sand compared to its gradation.... 14

6. Normalized histogram of Shape Index of three sands ................................... 17

7. Normalized histogram of Roundness Index of three sands ............................ 17

\section{LIST OF TABLES}

Table

Page

1. Basic measurements using test patterns ............................................... 13

2. Indices of shape for circular and square test patterns ................................ 15

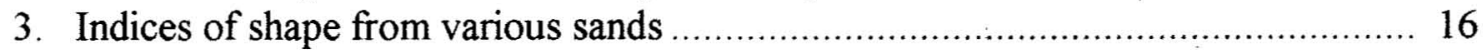




\section{CHAPTER 1: INTRODUCTION AND OBJECTIVES}

\section{Problem}

The Federal Highway Administration's Technical Advisory T-2040.24 of April 1989 recommends limiting the use of natural sands to 15 to 20 percent of the total aggregate used in asphalt pavement mixes. States must bear an increased cost for highway construction due to the additional costs to deliver manufactured sands to the construction site. Natural sands have been shown to be unstable, and fine particle shape has a greater influence on pavement performance than coarse particle shape. ${ }^{(1,2)}$ Crushed or manufactured aggregate is used in mix designs to achieve an acceptable angularity of the aggregate. Generally, natural sands tend to be rounded whereas manufactured sands tend to be angular. However, some natural sands are subangular and some crushed sands are not completely angular.

The literature shows that aggregate angularity, gradation, bulk density, and void content are all factors which determine pavement resistance to rutting. (See references 1, $2,3,4,5,6$.) Various methods have been developed to evaluate the performance of mix designs. Examples include the Marshall Apparatus, the Gyratory Testing Machine, and the Georgia Loaded Wheel Tester. In a recent study by Stuart and Mogawer, these machines failed to differentiate poor quality sands from the good quality sands in mixture tests. (7) However, the flow rate method using National Aggregate Association (NAA) Method A methods, the NAA Method A, and American Society for Testing Materials (ASTM) Method D3398 did successfully predict how the sands would perform in pavements. These methods indirectly measure the shape and texture of sand, which are known to correlate with the performance of asphalt pavements, but leave the researcher with little insight into the mechanisms of pavement deformation.

Direct methods measure one or more parameters on a particle by particle basis. The Corps of Engineers' Method CRD-C120-55 requires observation through a microscope to evaluate sieved samples for elongated particles. As early as 1960, Laughin used photographic enlargements to measure the angularity of particles retained on various sieves. ${ }^{\left({ }^{8}\right)}$ Recently, Barksdale, et al. used a digitizing table and a personal computer to quantify and analyze images captured by photography and xerography. ${ }^{(9)}$ Also, he measured the height of particles either by using a caliper or by using a special technique where the length of the shadow of individual particles were measured. $\mathrm{Li}$, et al. has suggested that computer-based fractal analysis be used to develop a performance index for aggregate. ${ }^{(10)}$ Landis developed a prototype computer-based video imaging system for the analysis of fine aggregate.(11) These recent advances in direct measurement of single particles provide compelling evidence that video imaging and computer technology can be effectively combined to produce an instrument to directly quantify the shape and possibly texture of aggregate. 
Aggregate measurement by video is a multi-step process involving video imaging, image capture, feature extraction, and statistical analysis. Each step in the process, starting with sampling and ending with the final evaluation, is an effort to reduce the amount of data required to describe an object. Usually the process is based on intuition, physical considerations, or purely mathematical techniques. For example, the area, perimeter, aspect ratio, or fractal dimension of a particle may be extracted from a video image of a particle and used to represent the particle in the analysis of the aggregate mix.

\section{Objectives}

The primary objective of the study was to develop a computer-based imaging system to acquire images of sufficient resolution and magnification for aggregate analysis and to address the problem of determining which features should be extracted and analyzed. Component availability, ease of use, and accuracy were important considerations in the design of the instrumentation.

A summary of project goals follow:

1. Build a computer controlled sample transport mechanism for the imaging system.

2. Build a video imaging system that will accurately display fine sand (+200 sieve).

3. Design and implement a video capture system.

4. Develop software to identify and separate objects, to extract the edge of each object, and to write the data to a standard file structure.

5. Develop software to correct for the aspect ratio of the video system and to extract the major features of an object.

6. Correlate aggregate features with performance. 


\section{CHAPTER 2: INSTRUMENTATION}

\section{Video System}

Samples were imaged with a Hitachi KP-C553 charge coupled device (CCD) color camera. The KP-C553 camera provided 512 by 480 pixel resolution, direct RGB outputs, adjustable electronic shutter speeds, and standard lens mounting to allow a variety of lenses to be fitted to the camera. Red/Green/Blue (RGB) components of the image were separately sent to a Data Translation DT2871 video capture (digitizing) circuit board, which was installed in the computer. A separate video monitor connected to the DT2871 allowed real-time viewing of images, either from the CCD camera or from the DT2871 digital memory.

RGB color-separated images are directly captured by the DT 2871 into three separate image buffers. Each buffer in the DT2871 consists of a 512 by 512 byte array ( 8 bits each) for a total color resolution of 24 bits. However, the useful image space was limited to 512 by 480 pixels by the camera resolution. The buffers containing the image data are mapped into the extended memory of the computer and are easily accessible by software. Data acquisition was facilitated by the Aurora C Function Library from Data Translation.

\section{Sample Transport}

A Velmex UniSlide Motor Driven Positioning System (XY table) and Velmex NF90 Stepping Motor Controller provided the positioning function required for automated data capture. Samples were placed on the XY table, with the camera focused on the table's base plate. The NF90 interfaced the XY table to the computer's serial port and allowed complete software control of sample position. Simple commands sent through the serial port were interpreted by the NF90 and converted into stepping motor control signals for the $X Y$ table. The $X Y$ table had a maximum travel of $150 \mathrm{~mm}$ both $X$ and $Y$ directions allowing samples to be spread over a $22,500 \mathrm{~mm}^{2}$ area.

\section{Illumination}

Initially, three DC-powered Walden Halogen Lamps provided sample illumination and were placed above at about a $45^{\circ}$ angle to the sample. The illumination intensity was adjusted along with camera exposure settings to give good image contrast and uniform sample illumination. Sample illumination provided a means of discriminating an object from background. Light-colored samples were placed on a dark background, and darkcolored samples were placed on a white background. Finally, the sample illumination was adjusted to give maximum sample to background contrast. 
Samples that contained a mixture of color proved difficult to deal with. Recent experiments demonstrated that back-lighting of the sample on a clear surface provided the best sample to background contrast. In this scheme, one lamp was aligned along the Zaxis toward the camera from beneath the sample with a white translucent Delrin plate providing diffusion. Samples were placed on a clear Lexan plate, with the camera focused on the sample plane. Sample illumination remained constant, since the lamp was always aligned with the camera; and, the sample transport was easily mounted to the translucent diffusing plate and clear sample plate. Figure 1 is a view of the XY table, Delrin diffuser, and Lexan sample plate. The image was captured with the digital imaging system. This scheme is analogous to a back-lighted microscope with movable stage.

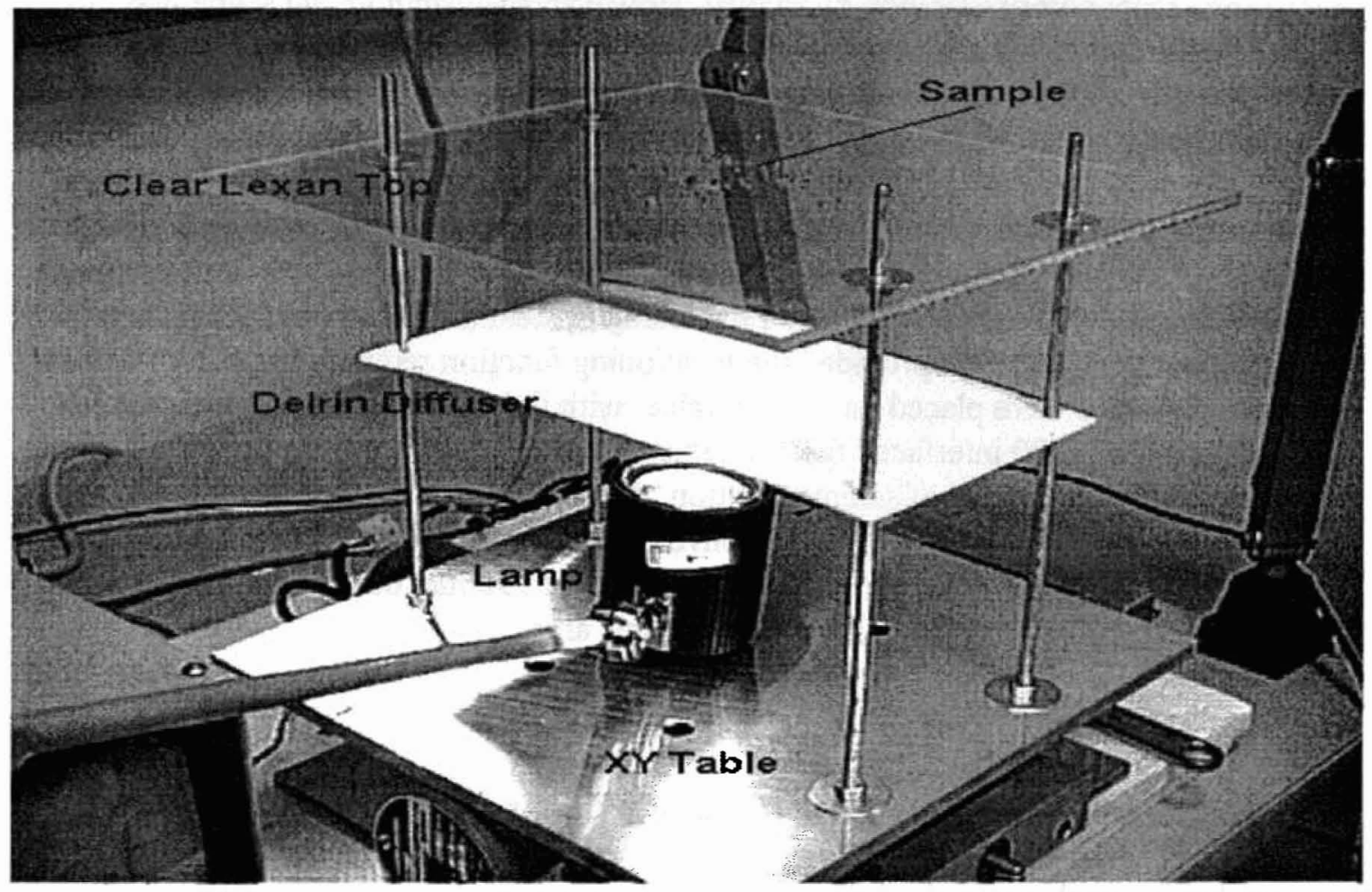

Figure 1. A view of the XY table, Delrin diffuser, and Lexan sample plate. 


\section{Data Capture Software}

The Data Capture Software is able to:

a. Identify and separate objects on the image.

b. Extract the edge of that object.

c. Store the image coordinates of the object's edge in a data file.

d. Control the sample transport system (the sample's position).

e. Provide data allowing for accurate object size calculation.

e. Provide data allowing for accurate video aspect ratio correction.

Identification and separation of objects in the image requires that the sample intensity (brightness) differ from the background intensity. To aid this determination, an image with both sample and background was captured and analyzed by a subroutine which produced an intensity histogram of the image. Ideally, two easily separable peaks are seen, one peak being background and the other being aggregate. Between these peaks, an intensity threshold was chosen. Any pixel whose intensity matched the background was completely blacked out (zero intensity). All other pixels were assumed to belong to an object and were changed to full intensity.

Next, the edge of each object was extracted using an algorithm described by Tamanaha. ${ }^{(12)}$ To detect and isolate objects, the entire image was scanned pixel-by-pixel beginning in the upper left corner. When an object was detected, the coordinates of that first pixel were saved. Then, the edge extraction routine searched for any adjacent pixels beginning in a counter-clockwise direction. If one was found, its coordinates were saved. This process continued until no more pixels were found, or the next pixel detected was the first pixel of that object. The entire process is depicted in figure 2. At this point, all pixel coordinates were saved to a VEC data file (see appendix A), and the process continued until the entire image had been scanned. The XY table was moved after each image was processed and data from multiple images were consolidated into a single data file.

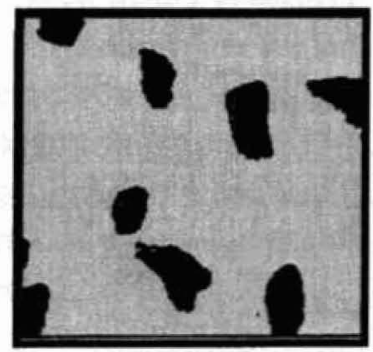

a.

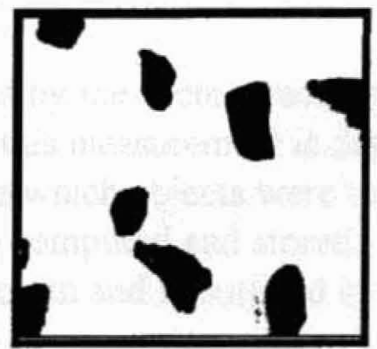

b.

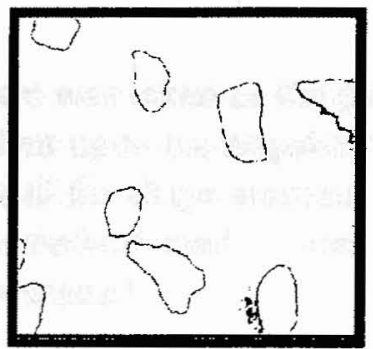

c.

Figure 2. a) Original image. b) Object discrimination. c) Edge trace. 
Two other subroutines were developed to increase the capture software's utility: (1) a calibration subroutine, discussed in the next section, and (2) a histogram routine which allows analysis of sample and background intensity, and appropriate adjustments to intensity threshold settings.

\section{Calibration Procedure}

To ensure that particles were accurately measured, the system was calibrated as follows:

A. An object of known size was placed in the imaging field, either a clear calibration reticle, or squares printed with a laser printer and measured manually.

B. The object was captured and processed to find the edge of all objects in the field of view.

C. The distance in pixels was determined between two known points, both horizontally and vertically.

D. A program calculates calibration scale factors for horizontal and vertical dimensions in units of millimeters per pixel.

Any disturbance or change in the hardware that physically affected the video system also affected the calibration. Therefore, changing lenses or camera position required that the system be re-calibrated. During calibration, lens identification and imaging distance was manually entered and saved along with the calibration data in a complementary data file designated as MET files.

\section{Sample Dispersion}

The samples were simply poured onto the sample plate and examined under the magnification of the video system. To keep objects from touching, large objects were manually separated and, for sand, the sample plate was gently tapped until individual particles no longer touched. Additional experimentation will need to be done to find an appropriate technique to automatically disperse the samples. 


\section{CHAPTER 3: FEATURE EXTRACTION}

\section{Simulation Data}

Prior to the development of the analysis software, several programs were developed to produce exact test data as specified in the File Protocol. See Appendix A for a description of VEC and MET files. The vector trace of squares, circles, ellipses, triangles, and arbitrary polygons were computed and output in the VEC data file format. These (simulated) objects were scaled, rotated, and translated to produce a variety of objects of exact dimensions. The MET data file was also created simultaneously. These data files provided a means to debug and verify the analysis software independent of the video imaging system.

\section{Basic Measurements}

Care was taken in the development of the analysis software to avoid analyzing partial or incomplete objects. Some objects extend outside the field of view and can't be used in an analysis. Objects were rejected if any of the following problems were found:
A. Duplicate data point in the vector trace.
B. Pixel skipped (all pixel must be adjacent to another pixel).
C. First and last pixels the same.
D. Too large (the vector trace exceeded 3000 pixels).
E. Failure to close (a gap exists between the first and last pixels).
F. Incorrect trace sequence (the vector trace must always proceed in a counter- clockwise direction).

For each validated object, several basic measurements were made and then written to a file in a format compatible with spread sheet programs. Most of the measurements, including size and indices of shape, were corrected for the image scale factor (or aspect ratio) of the imaging system.

\section{a. Area and Perimeter}

The number of pixels recorded by the vector trace program was taken as the perimeter of the object in pixels. Although this measurement is dependent upon the angular rotation of a object, it was used to indicate which objects were too small for shape analysis. The pixel area of each object was also computed and stored. The method used to compute pixel area is based on Green's theorem and is outlined by Tamanaha. ${ }^{(12)}$

The video system was calibrated prior to data collection utilizing a calibration reticle or test pattern. The calibration data was expressed in $\mathrm{mm} /$ pixel for both the $\mathrm{X}$ and $\mathrm{Y}$ dimensions and was placed in the MET file for use by the analysis programs. Multiplying 
pixel coordinates by these "calibration factors" translated the coordinates of each video pixel such that the new coordinates represented actual coordinates of points on the perimeter of the object in physical space. This was done so that accurate size and shape measurements could be performed on the data set, regardless of the video system's aspect ratio or magnification.

To calculate the actual perimeter $(\mathrm{P})$ in millimeters, the physical coordinates of an object's edge were used. The distance between adjacent points was calculated by the Pythagorean theorem and summed to give the perimeter in millimeters. The area of one pixel was calculated by taking the product of the $\mathrm{X}$ and $\mathrm{Y}$ calibration factors, and the area (A) of an object was taken as the product of the area of one pixel and the number of pixels in the object (previously calculated).

\section{b. Length Measurements and Aspect Ratio}

Three length measurements were made on each validated object - maximum caliper length (maximum length), minimum caliper length (width), and the corresponding caliper length orthogonal to the width (length). See figure 3 . The width divided by the length was taken as the aspect ratio. In most cases the aspect ratio would be equal to or at least similar to the Elongation Ratio (intermediate length divided by greatest length).

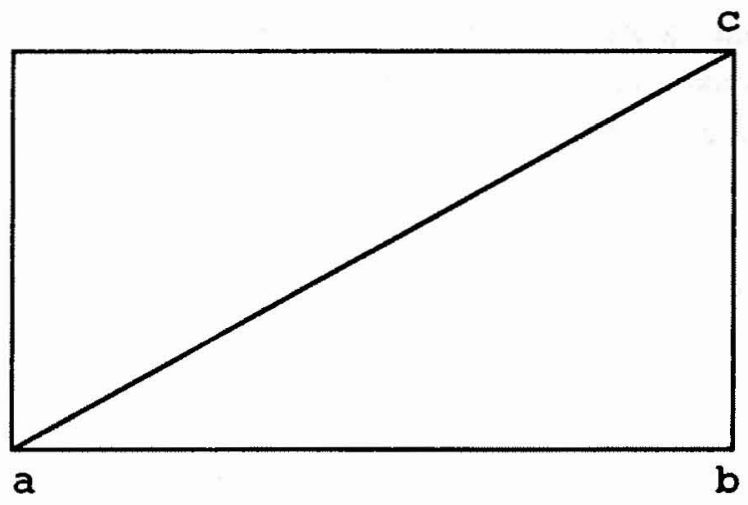

Figure 3. Definition of width, length; and maximum length. Segment bc is the width, segment $a b$ is the length, and segment $a c$ is the maximum length.

All length measurements were calculated from the data points representing the physical edge of each object. The calculation is straightforward and proceeds as follows: First, the centroid of the edge data points describing the edge of the object is computed. Then, the data points are linearly translated to a Cartesian coordinate system so that the centroid lies on the origin. The data set is rotated in $1^{\circ}$ increments through $180^{\circ}$. At each angle of rotation, all of the points are searched to find the extreme points relative to each axis. Effectively, this gives two, orthogonal caliper measurements at each position. The minimum separation of the extreme points is recorded as the width, and the simultaneous orthogonal measurement is the length. The maximum separation of any two points is taken as the maximum length. 


\section{Gradation}

The width (minimum caliper size) of a particle was used to determine if a particle would pass through a given sieve opening. By comparing the width to each sieve size in sequence starting from the largest sieve size, the sieve that would retain each particle was found. Since gradation is based on weight, an approximation to weight was needed. Therefore, the following relationship was assumed to be true.

$$
\mathrm{W}_{\mathrm{i}} \propto\left(\mathrm{A}_{\mathrm{i}}\right)^{3 / 2} \text { where, }
$$

$\mathrm{W}_{\mathrm{i}}$ is the weight of a particle, and $\mathrm{A}_{\mathrm{i}}$ is the area of the particle measured by the video system. When computing volume fraction for the gradation curve, the constant of proportionality divided out. The assumption made in equation (1) is equivalent to assuming that variations in shape and density are insignificant over the entire gradation curve. In addition to the sieve equivalent gradation, the volume cumulative distribution was computed from the data set using equation (1).

\section{CAPP Index and EAPP Index}

For a specific object, square, circle, or some arbitrary shape, the area divided by the perimeter squared $\left(\mathrm{A} / \mathrm{P}^{2}\right)$ is independent of the size of the object. Therefore, the potential exists to utilize this property for a size independent index of shape (known as generalized $\pi$ indices) for a few special cases. For example, a circle has the maximum area for a given perimeter. Therefore, a large $\mathrm{A} / \mathrm{P}^{2}$ should indicate a circular object. By definition, the CAPP index of an object is the area divided by the perimeter squared normalized by the $\mathrm{A} / \mathrm{P}^{2}$ of a circle so that:

$$
\mathrm{CAPP}=4 \pi \mathrm{A} / \mathrm{P}^{2} \quad \text { where, }
$$

CAPP is the objects' A/P2 scaled to give a value of 1.0 for a circle, $A$ is the area of the object in square millimeters, and $P$ is the perimeter of the object in millimeters.

The CAPP Index is 1.0 for a circle and becomes smaller for irregular particles which potentially makes it useful for identifying rounded particles. However, some particles may be smooth but not circular. In an attempt to utilize the properties of $A / P^{2}$ to identify these particles, a second index was developed. By definition, the EAPP index of an object is the area divided by the perimeter squared normalized by the $A / P^{2}$ of an ellipse of the same aspect ratio so that:

$$
\mathrm{EAPP}=\left(2 \pi \mathrm{A} / \mathrm{P}^{2}\right)(\mathrm{L} / \mathrm{W}+\mathrm{W} / \mathrm{L}) \text { where, }
$$

EAPP is the objects' $\mathrm{A} / \mathrm{P}^{2}$ scaled to give a value of 1.0 for an ellipse of the same aspect ratio, 
$A$ is the area of the object in square $\mathrm{mm}$,

$P$ is the perimeter of the object in $\mathrm{mm}$,

$\mathrm{W}$ is the width of the object in $\mathrm{mm}$, and

$\mathrm{L}$ is the length of the object in $\mathrm{mm}$.

The EAPP Index was intended to identify smooth but non circular objects.

\section{Hough Transform}

The Hough transform involves the transformation of a line in Cartesian coordinate space to a point in polar coordinate space. ${ }^{(13)}$ Computing the Hough transform of the points that define the edge of a particle produces a data set that can easily be used to describe that particle in terms of the length of any straight edges and the angles between those straight edges. However, the Hough transform is dependent upon the size and position, with respect to the origin of its Cartesian coordinate system, of the object to be transformed. To solve this problem, each object was translated and scaled to effectively normalize the objects' size and position. The angular orientation of the object is unimportant here.

The computation of the normalized Hough transform is straight forward and is described below:

1. For each object, read the edge data from the disc data file and scale the position of each point by the calibration scale factors to find the points the correspond the physical edge of the object.

2. Find the centroid of the edge data points (mean $x$ coordinate and mean $y$ coordinate) and translate the data set so that the centroid is at the origin. This is done by subtracting the mean $\mathrm{x}$ and mean $\mathrm{y}$ values from the $\mathrm{x}$ and $\mathrm{y}$ values of each point in the data set.

3. Search the data for the point that lies the farthest from the origin. Use that distance as a normalizing distance for each data point and scale the position of each data point so that the outermost point(s) lie on a unit circle while the shape of the object is preserved.

4. Compute the Hough transform of the data points that make up the edge of the object. The resulting Hough transform is a two dimensional integer array $\mathrm{H}(\mathrm{r}, \theta)$ in polar coordinates. In practice, the array was dimensioned as $\mathrm{H}(100,120)$ so that the linear resolution (r) was 1 percent and the angular resolution $(\theta)$ was $3^{\circ}$.

A brief description of the algorithm used to compute the Hough transform follows. A straight line can be parametrically described by

$$
r=x \cos (\theta)+y \sin (\theta)
$$

where $r$ is the normal distance from the origin to the line and $\theta$ is the angle of the normal with respect to the $\mathrm{x}$ axis. To compute the Hough transform of discrete data points, a two 
dimension array is created where each cell (element) in the array represents a distance ( $r$ ) and angle $(\theta)$. For each point in the edge of the object, a number of cells in the Hough space are incremented. For each possible value of the integer $\theta$, the value of $r$ is computed and the resulting values of $r$ and $\theta$ are used to point to the cell in the array $H(r, \theta)$ that is to be incremented. This process is repeated for all values of $\theta$ (every $3^{\circ}$ ) for each object. Each point will result in a sinusoidal pattern of cells to be incremented. The resulting process produces the Hough transform for a binary image (discrete points).

\section{Roundness Index and Shape Index}

After the Hough transform is computed, two indices of shape can be extracted: Roundness, a measure of roundness, and Shape (a measure angularity). As described above, the normalized Hough transform simplifies the process of measuring the length of straight lines and finding the angles between those lines. The number of times a cell in the Hough transform was incremented gives the number of points that fell on or near the straight line described by the value of $r$ and $\theta$ for that cell. See figure 4 . The length of a line is computed by multiplying the point to point spacing, a function of both the $\mathrm{X}$ and $\mathrm{Y}$ calibration factors and $\theta$, times one minus the cell value (number of points along the line).

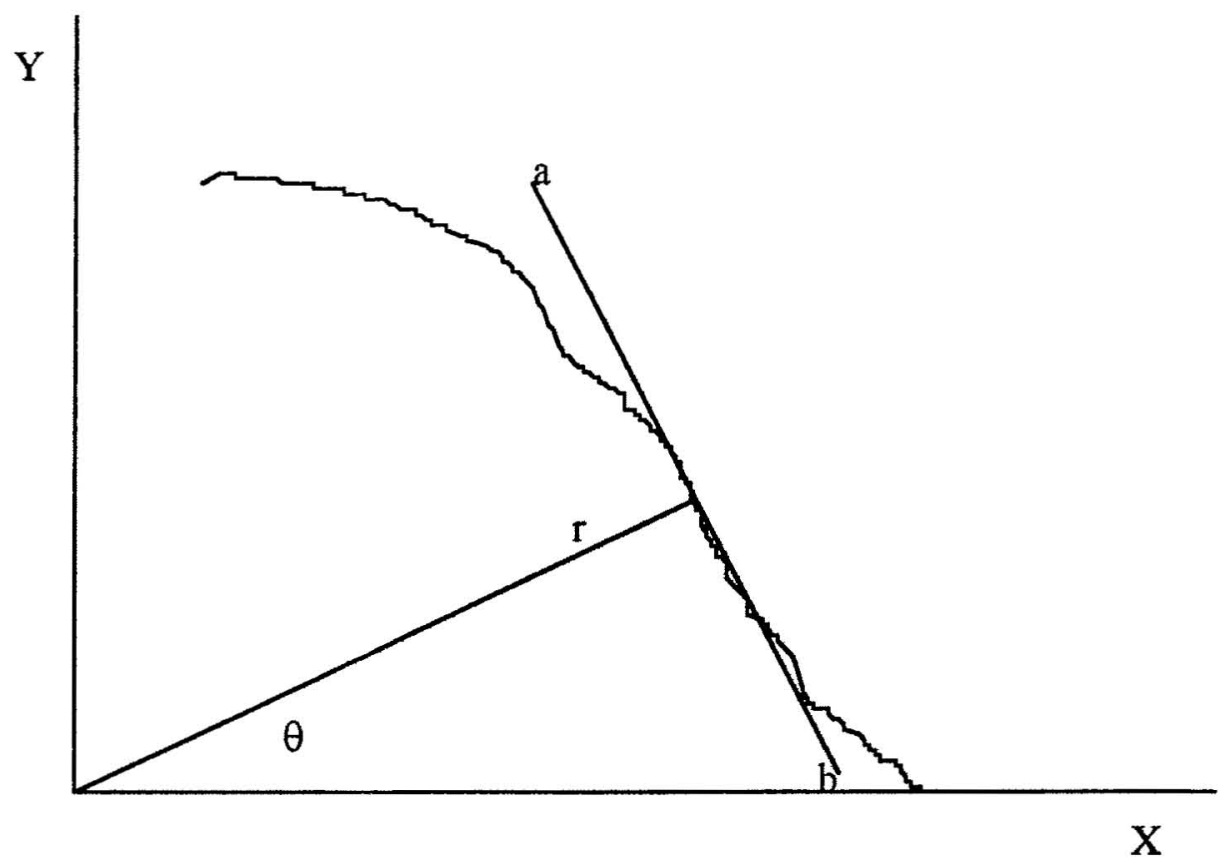

Figure 4. Hough transform example. All points that lie on or close to line segment ab will be counted and placed into the Hough transform cell found at coordinates $r$ and $\theta$. 


\section{a. Roundness Index}

When analyzing natural materials, it is desirable to have an index related to the roundness of the particles so that circular objects (assumed to be spherical particles) can be identified. From the two dimensional Hough transform $\mathrm{H}(\mathrm{r}, \theta)$, a line density function, $R(r)$, was computed by summing the rows of $H(r, \theta)$ as follows:

$$
R(r)=\sum_{i} H\left(r, \theta_{i}\right)
$$

The function $\mathrm{R}(\mathrm{r})$ can be thought of a describing how the straight line segments are distributed as a function of distance from the center of the object. $R(r)$ is searched for a maximum, which occurs at $r=r_{p}$. The value $r_{p}$ gives the distance from the centroid which has the highest density of points that lie along straight line segments. The value of the pointer $r$ can vary from zero to a maximum value of $r_{m}$. In our system, $r_{m}$ is set equal to 100. The Roundness Index is then defined as

$$
R_{i}=r_{p} / r_{m} \quad \text { where }
$$

If the object is circular, then the position of the maximum density of line segments (two points or more in length) will be on or near the unit circle defined by $\mathrm{r}_{\mathrm{m}}$, and the Roundness Index will be one.

\section{b. Shape Index}

The Shape Index is strongly related to the observed angularity of the particles, and, in principle, can be used to estimate the performance of the aggregate. To compute the Shape Index, $S_{\mathfrak{j}}$, first develop the function $A(\theta)$ which is simply the peak values of $H(r, \theta)$ as a function of $\theta$. Then search $A(\theta)$ for the largest value, $A_{m}$, which should also be the largest value in all of $\mathrm{H}(\mathrm{r}, \theta)$ and the length of the longest line segment in the object. Also, $\overline{\mathrm{A}}$ the average of the lengths found in $\mathrm{A}(\theta)$ are computed, and then

$$
\mathrm{S}_{\mathrm{i}}=1-\left(\overline{\mathrm{A}} / \mathrm{A}_{\mathrm{m}}\right)
$$

$S_{i}$ may be thought of as 1 minus the average line length divided by the longest line length. If one or two lines dominate the perimeter of the object, $S_{i}$ will approach unity. If the object is irregular or rounded, then all of the lines are short and near the average length and $\mathrm{S}_{\mathrm{i}}$ approaches zero. 


\section{CHAPTER 4: RESULTS}

\section{Measurement of Basic Parameters}

Multiple images of squares and circles of known size were printed by a laser printer onto a white sheet of paper. The patterns were verified for accuracy and then used as test patterns to determine the performance of the imaging system and measurement software. The test patterns were presented to the camera at $0^{\circ}, 30^{\circ}, 45^{\circ}$, and $90^{\circ}$ and then analyzed. The results of the linear measurements are summarized in table 1 .

Table 1. Basic measurements using test patterns.

\begin{tabular}{|c|c|c|c|c|c|c|}
\hline Pattern & $\begin{array}{l}\text { Width } \\
\text { (mm) }\end{array}$ & $\begin{array}{c}\text { Length } \\
(\mathrm{mm})\end{array}$ & $\begin{array}{l}\text { Maximum } \\
\text { Length } \\
\text { (mm) }\end{array}$ & $\begin{array}{c}\text { Perimeter } \\
(\mathrm{mm})\end{array}$ & $\begin{array}{c}\text { Area } \\
\left(\mathrm{mm}^{2}\right)\end{array}$ & $\begin{array}{l}\text { Aspect } \\
\text { Ratio }\end{array}$ \\
\hline $\begin{array}{c}8.2 \mathrm{~mm} \text { square } \\
\text { Mean (n=15) } \\
\text { percent error } \\
\text { Std. Dev. }\end{array}$ & $\begin{array}{c}7.88 \\
-3.9 \\
0.21 \\
\end{array}$ & $\begin{array}{c}7.99 \\
-2.6 \\
0.20 \\
\end{array}$ & $\begin{array}{r}10.64 \\
-8.25 \\
0.12 \\
\end{array}$ & $\begin{array}{l}31.61 \\
-3.6 \\
1.31 \\
\end{array}$ & $\begin{array}{c}60.11 \\
-10.6 \\
2.08 \\
\end{array}$ & $\begin{array}{c}0.987 \\
-1.3 \\
0.0082 \\
\end{array}$ \\
\hline $\begin{array}{c}16.2 \mathrm{~mm} \text { square } \\
\text { Mean }(\mathrm{n}=8) \\
\text { percent error } \\
\text { Std. Dev. }\end{array}$ & $\begin{array}{c}16.32 \\
0.7 \\
0.13 \\
\end{array}$ & $\begin{array}{c}16.45 \\
1.5 \\
0.14 \\
\end{array}$ & $\begin{array}{c}22.35 \\
-2.4 \\
0.09 \\
\end{array}$ & $\begin{array}{c}66.66 \\
2.9 \\
2.35 \\
\end{array}$ & $\begin{array}{c}258.85 \\
-1.4 \\
3.08 \\
\end{array}$ & $\begin{array}{l}0.992 \\
-0.8 \\
0.0065 \\
\end{array}$ \\
\hline $\begin{array}{c}32.2 \mathrm{~mm} \text { square } \\
\text { Mean }(\mathrm{n}=2) \\
\text { percent error } \\
\text { Std. Dev. }\end{array}$ & $\begin{array}{c}32.07 \\
-0.4 \\
0.40 \\
\end{array}$ & $\begin{array}{c}32.76 \\
1.7 \\
0.21 \\
\end{array}$ & $\begin{array}{c}45.08 \\
-1.0 \\
0.00 \\
\end{array}$ & $\begin{array}{r}129.66 \\
0.67 \\
0.66 \\
\end{array}$ & $\begin{array}{c}1026.50 \\
-1.0 \\
8.60 \\
\end{array}$ & $\begin{array}{l}0.979 \\
-2.1 \\
0.0186 \\
\end{array}$ \\
\hline $\begin{array}{c}8.2 \mathrm{~mm} \text { circle } \\
\text { Mean }(\mathrm{n}=11) \\
\text { percent error } \\
\text { Std. Dev. }\end{array}$ & $\begin{array}{c}7.66 \\
-6.6 \\
0.12 \\
\end{array}$ & $\begin{array}{c}7.83 \\
-4.5 \\
0.18 \\
\end{array}$ & $\begin{array}{c}8.04 \\
-2.0 \\
0.18\end{array}$ & $\begin{array}{c}26.33 \\
2.2 \\
0.64 \\
\end{array}$ & $\begin{array}{c}47.35 \\
-10.0 \\
1.55 \\
\end{array}$ & $\begin{array}{l}0.979 \\
-2.1 \\
0.0114\end{array}$ \\
\hline $\begin{array}{c}16.2 \mathrm{~mm} \text { circle } \\
\text { Mean }(\mathrm{n}=6) \\
\text { percent error } \\
\text { Std. Dev. }\end{array}$ & $\begin{array}{c}15.84 \\
-2.2 \\
0.12 \\
\end{array}$ & $\begin{array}{c}16.01 \\
-1.2 \\
0.09 \\
\end{array}$ & $\begin{array}{c}16.28 \\
0.5 \\
0.13 \\
\end{array}$ & $\begin{array}{c}54.05 \\
6.2 \\
0.39 \\
\end{array}$ & $\begin{array}{c}200.43 \\
-2.8 \\
3.15 \\
\end{array}$ & $\begin{array}{c}0.990 \\
-1.0 \\
0.0067 \\
\end{array}$ \\
\hline $\begin{array}{c}32.2 \mathrm{~mm} \text { circle } \\
\text { Mean }(\mathrm{n}=3) \\
\text { percent error } \\
\text { Std. Dev. }\end{array}$ & $\begin{array}{l}32.10 \\
-0.3 \\
0.20 \\
\end{array}$ & $\begin{array}{c}32.26 \\
0.2 \\
0.25 \\
\end{array}$ & $\begin{array}{c}32.64 \\
1.4 \\
0.25 \\
\end{array}$ & $\begin{array}{c}110.09 \\
8.8 \\
0.95 \\
\end{array}$ & $\begin{array}{c}815.54 \\
0.1 \\
10.74 \\
\end{array}$ & $\begin{array}{l}0.995 \\
-0.5 \\
0.0046 \\
\end{array}$ \\
\hline
\end{tabular}


The basic measure of length in a digital imaging system is the pixel. For the magnification used the $8.2 \mathrm{~mm}$ squares were approximately 36 pixels in length. Therefore, an error of one pixel caused approximately a 2.8 percent error in linear measurement for the $8.2 \mathrm{~mm}$ objects.

\section{Gradation}

Data from several sands were used to compute the gradation and the cumulative volume distributions described in chapter 3 , section 3 . As a typical example of the sands analyzed, the cumulative volume distribution from Ottowa sand is compared with the sieve analysis of the same sample in figure 5 .

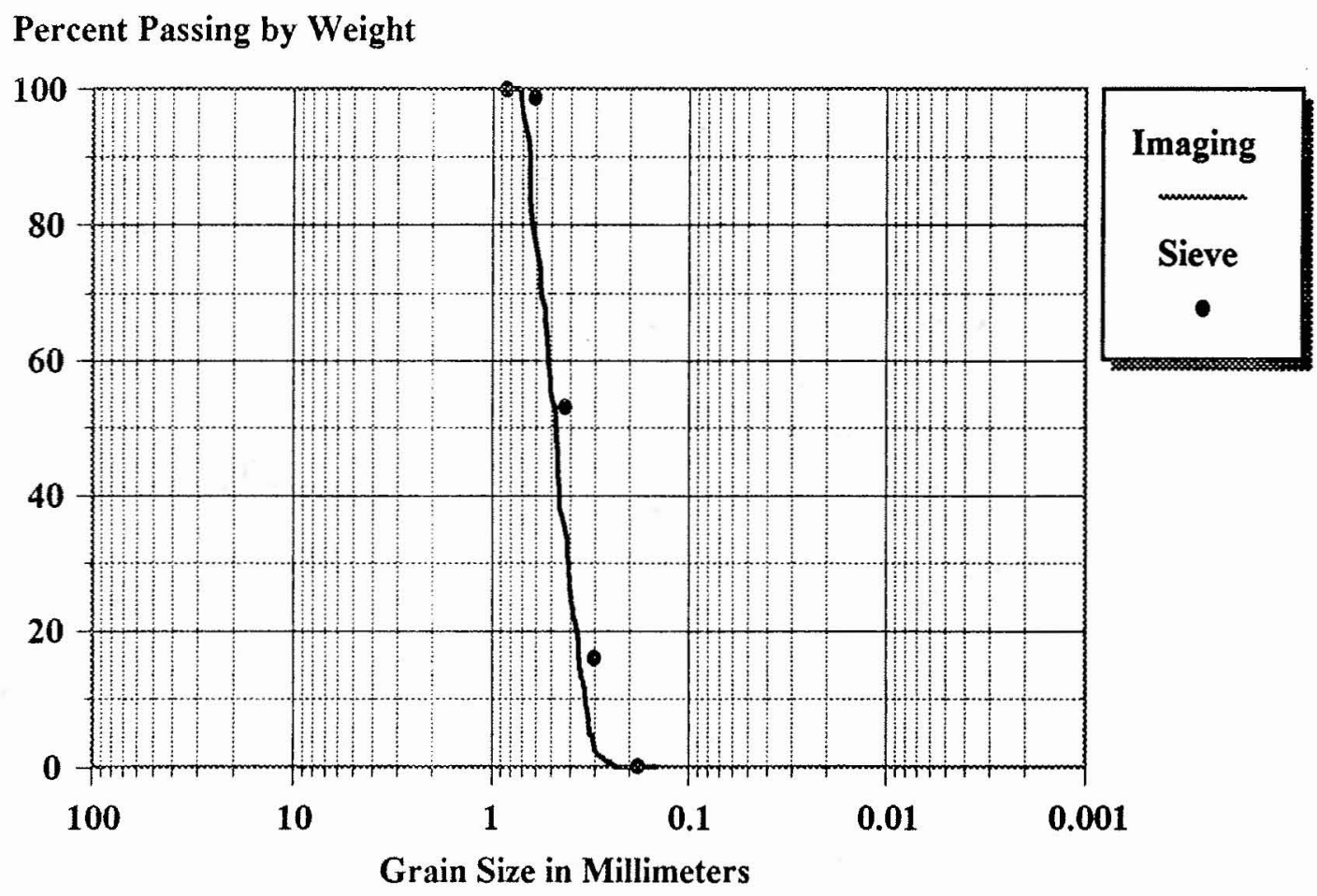

Figure 5. The cumulative volume distribution of Ottawa sand compared to its gradation.

\section{CAPP, EAPP, Roundness, and Shape Indices}

The CAPP, EAPP, Roundness, and Shape indices were computed from test pattern data and the results are summarized in table 2 . Several sands were also analyzed and the data is presented in table 3 . Two manufactured sands (highest quality) and four natural sands from the state of Arkansas are listed in table 3 along with Ottowa sand which contains a high percentage of uniform spherical particles. The Arkansas sands are ordered in accordance with observed performance. The last column in table 3 is the percentage of particles which had a Shape Index greater than 0.600 . An example of the distribution of 
the Shape Index is shown in figure 6, and an example of the Roundness Index is show in figure 7 .

Table 2. Indices of shape for circular and square test patterns.

\begin{tabular}{|c|c|c|c|c|}
\hline Pattern & CAPP & EAPP & Roundness & Shape \\
\hline $\begin{array}{c}8.2 \mathrm{~mm} \text { square } \\
\text { Mean }(n=15) \\
\text { Std. Dev. }\end{array}$ & $\begin{array}{l}0.758 \\
0.046\end{array}$ & $\begin{array}{l}0.758 \\
0.046\end{array}$ & $\begin{array}{l}0.726 \\
0.009\end{array}$ & $\begin{array}{l}0.785 \\
0.046\end{array}$ \\
\hline $\begin{array}{c}16.2 \mathrm{~mm} \\
\text { square } \\
\text { Mean }(n=8) \\
\text { Std. Dev. }\end{array}$ & $\begin{array}{l}0.734 \\
0.047\end{array}$ & $\begin{array}{l}0.734 \\
0.047\end{array}$ & $\begin{array}{l}0.713 \\
0.004\end{array}$ & $\begin{array}{l}0.827 \\
0.014\end{array}$ \\
\hline $\begin{array}{c}32.2 \mathrm{~mm} \\
\text { square } \\
\text { Mean }(n=2) \\
\text { Std. Dev. }\end{array}$ & $\begin{array}{l}0.767 \\
0.001\end{array}$ & $\begin{array}{l}0.768 \\
0.001\end{array}$ & $\begin{array}{l}0.708 \\
0.000\end{array}$ & $\begin{array}{l}0.839 \\
0.017\end{array}$ \\
\hline $\begin{array}{c}8.2 \mathrm{~mm} \text { circle } \\
\text { Mean }(\mathrm{n}=11) \\
\text { Std. Dev. }\end{array}$ & $\begin{array}{l}0.858 \\
0.018\end{array}$ & $\begin{array}{l}0.856 \\
0.018\end{array}$ & $\begin{array}{l}0.930 \\
0.014\end{array}$ & $\begin{array}{l}0.458 \\
0.082\end{array}$ \\
\hline $\begin{array}{c}16.2 \mathrm{~mm} \text { circle } \\
\text { Mean }(\mathrm{n}=6) \\
\text { Std. Dev. }\end{array}$ & $\begin{array}{l}0.862 \\
0.004\end{array}$ & $\begin{array}{l}0.862 \\
0.004\end{array}$ & $\begin{array}{l}0.954 \\
0.007\end{array}$ & $\begin{array}{l}0.308 \\
0.034\end{array}$ \\
\hline $\begin{array}{c}32.2 \mathrm{~mm} \text { circle } \\
\text { Mean }(\mathrm{n}=3) \\
\text { Std. Dev. }\end{array}$ & $\begin{array}{l}0.846 \\
0.005\end{array}$ & $\begin{array}{l}0.846 \\
0.005\end{array}$ & $\begin{array}{l}0.963 \\
0.005\end{array}$ & $\begin{array}{l}0.237 \\
0.016\end{array}$ \\
\hline
\end{tabular}


Table 3. Indices of shape from various sands

\begin{tabular}{|c|c|c|c|c|c|}
\hline Sand & $\overline{\text { CAPP }}$ & $\overline{\text { EAPP }}$ & Roundness & Shape & $\begin{array}{l}S_{\mathrm{i}}>0.6 \\
\text { Percent }\end{array}$ \\
\hline $\begin{array}{c}\text { Donnafill } \\
\text { (manufactured) } \\
\text { Mean }(n=58) \\
\text { Std. Dev. }\end{array}$ & $\begin{array}{l}0.640 \\
0.092\end{array}$ & $\begin{array}{l}0.703 \\
0.085\end{array}$ & $\begin{array}{l}0.596 \\
0.181\end{array}$ & $\begin{array}{l}0.604 \\
0.084\end{array}$ & $53 \%$ \\
\hline $\begin{array}{c}\text { Westfork } \\
\text { (manufactured) } \\
\text { Mean }(n=60) \\
\text { Std. Dev. }\end{array}$ & $\begin{array}{l}0.634 \\
0.169\end{array}$ & $\begin{array}{l}0.687 \\
0.162\end{array}$ & $\begin{array}{l}0.523 \\
0.215\end{array}$ & $\begin{array}{l}0.558 \\
0.076\end{array}$ & $23 \%$ \\
\hline $\begin{array}{c}\text { VanBuren } \\
\text { natural sand } \\
\text { Mean }(n=234) \\
\text { Std. Dev. }\end{array}$ & $\begin{array}{l}0.660 \\
0.150\end{array}$ & $\begin{array}{l}0.705 \\
0.141\end{array}$ & $\begin{array}{l}0.553 \\
0.240\end{array}$ & $\begin{array}{l}0.541 \\
0.077\end{array}$ & $21 \%$ \\
\hline $\begin{array}{c}\text { Bourgham } \\
\text { natural sand } \\
\text { Mean }(n=82) \\
\text { Std. Dev. }\end{array}$ & $\begin{array}{l}0.690 \\
0.149\end{array}$ & $\begin{array}{l}0.727 \\
0.139\end{array}$ & $\begin{array}{l}0.639 \\
0.196\end{array}$ & $\begin{array}{l}0.536 \\
0.071\end{array}$ & $15 \%$ \\
\hline $\begin{array}{c}\text { Graham } \\
\text { natural sand } \\
\text { Mean }(n=72) \\
\text { Std. Dev. }\end{array}$ & $\begin{array}{l}0.654 \\
0.145\end{array}$ & $\begin{array}{l}0.694 \\
0.142\end{array}$ & $\begin{array}{l}0.620 \\
0.205\end{array}$ & $\begin{array}{l}0.533 \\
0.066\end{array}$ & $14 \%$ \\
\hline $\begin{array}{c}\text { Ingram } \\
\text { natural sand } \\
\text { Mean }(n=47) \\
\text { Std. Dev. }\end{array}$ & $\begin{array}{l}0.537 \\
0.144\end{array}$ & $\begin{array}{l}0.611 \\
0.144\end{array}$ & $\begin{array}{l}0.366 \\
0.235\end{array}$ & $\begin{array}{l}0.519 \\
0.068\end{array}$ & $13 \%$ \\
\hline $\begin{array}{c}\text { Ottawa } \\
\text { (silica) } \\
\text { Mean }(n=136) \\
\text { Std. Dev. }\end{array}$ & $\begin{array}{l}0.765 \\
0.108\end{array}$ & $\begin{array}{l}0.795 \\
0.079\end{array}$ & $\begin{array}{l}0.699 \\
0.192\end{array}$ & $\begin{array}{l}0.506 \\
0.074\end{array}$ & $11 \%$ \\
\hline
\end{tabular}


Normalized Fraction

Histogram of Shape Index

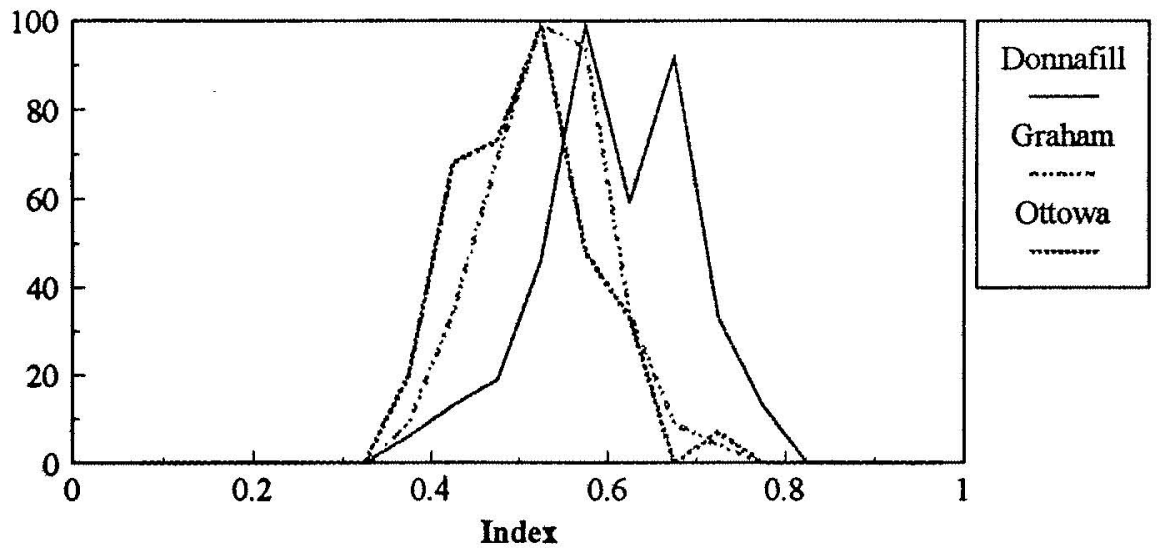

Figure 6. Normalized histogram of Shape Index of three sands.

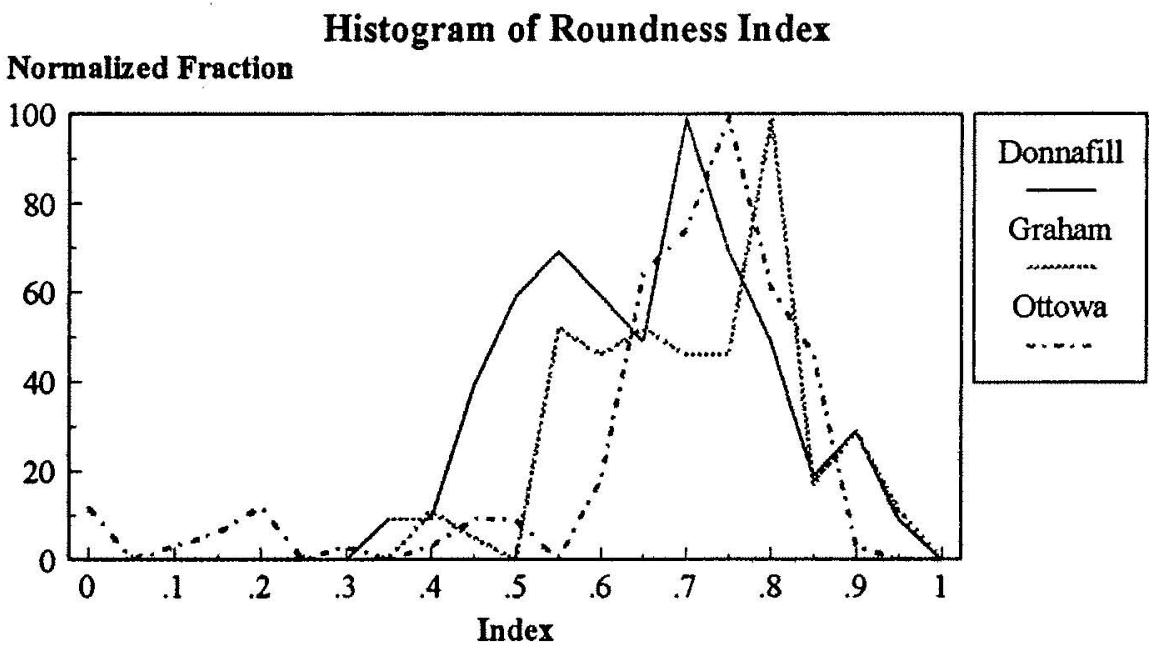

Figure 7. Normalized histogram of Roundness Index of three sands. 


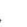




\section{CHAPTER 5: CONCLUSIONS AND RECOMMENDATIONS}

\section{Accuracy of Basic Measurements}

The instrumental accuracy for basic linear measurements was on the order of one or two pixels for most of the test patterns used. Refer to table 1. Accuracy varied with object size and improved as the test pattern became larger. This is a characteristic of all digital system when the measured quantity produces small values that must be represented by integer values. The published aspect ratio of the imaging system is $4: 5$ so that the image of a square should appear rectangular in the pixel space (one side reduce 20 percent). The software and calibration procedure successfully corrected for the system aspect ratio. Since the test patterns were squares and circles, the measured aspect ratio was expected to be 1.000 . The greatest error in aspect ratio was 2.1 percent, indicating that the shape of the test patterns were faithfully reproduced in the final edge data, independent of size and orientation.

The area and perimeter errors were somewhat greater than expected. For example, the $32.2 \mathrm{~mm}$ circle test pattern had only a 0.1-percent error in area, but had an 8.8-percent error in perimeter. This was understood by realizing that an edge tracing of discrete pixels can't exactly follow the smooth curve of a circle or a straight line that does not fall on a multiple of $45^{\circ}$. The resulting error is usually an over estimation of the perimeter which is a function of object orientation and shape.

\section{Gradation}

The gradation of Ottowa sand (from sieve data) is displayed in figure 5 with the cumulative volume distribution overlaid on the same graph. The cumulative volume distribution of Ottowa sand was selected for presentation because it has uniform spherical grains which would meet the assumptions made in deriving equation 1 . Our intention was to first test the accuracy of the linear measurements with less regard for developing a new method of measuring gradation. The cumulative volume distribution closely follows the gradation data but uniformly lies to the left. This at least implies that accurate relative size measurements can be made over the size range of interest for sands. Several possibilities exists to explain the differences between the gradation and the cumulative volume distribution but these were not studied.

\section{CAPP Index and EAPP Index}

The CAPP Index was developed to detect the presence of round (spherical) particles and should be exactly 1.00 for a circular object and 0.785 for a square object. However, the CAPP Indices were approximately 0.85 for the circular test patterns and 0.75 for square test patterns (refer to table 2). From the test pattern data (table 1), the measured area of an object was usually less than the actual area, and the measured perimeter was usually greater than the actual perimeter which would cause the CAPP Index and the 
to consistently be too small. The mean CAPP Index did not differentiate the natural sands from the manufactured sands and did not correctly rank the sands according to their accepted performance. Refer to table 3 .

The EAPP Index was developed to detect the presence of elliptical (rounded but not necessarily circular) objects and should be exactly 1.00 for an elliptical object. Also, if the object's aspect ratio is exactly 1.00 , which was the case for the all of the test patterns, then the EAPP Index should equal the CAPP Index. The mean EAPP Index did not differentiate the natural sands from the manufactured sands and did not correctly rank the sands according to their accepted performance. Refer to table 3 .

\section{Roundness Index and Shape Index}

The Roundness Index should be 1.00 for circular objects and 0.707 for square objects. The data in table 2 reveals that the Roundness Index comes much closer to expected values for the test patterns than either the CAPP Index or the EAPP Index and is therefore favored as a means of discriminating round objects. During the development of the Roundness Index, it was discovered that irregular objects (dirt) or clustered (touching) particles usually produced low values, typically 0.3 . Two examples from table 3 show the effectiveness of the Roundness Index to indicate these two extremes. The Ingram sand, which contains numerous irregular (dirt) particles had the lowest mean Roundness Index, and the Ottawa sand, which contains numerous round particles, had the highest mean Roundness Index.

The Shape Index was developed to differentiate angular particles from all other shapes and in general does so. Exact values for the Shape Index are difficult to calculate and explicit formulae have not been developed, therefore, we are relying on empirical data for now to indicate typical values. In practice, the Shape Index shows some dependence on size, especially for the smaller circular test pattern (see table 2), but still differentiates circular from square test patterns. During the development of the Shape Index, a value of 0.6 or more was observed as indicating angular material. The last column in table 3 indicates the percent (by count) of the sand that exceeds this somewhat arbitrary discrimination threshold for being classified as angular. Both the mean Shape Index and the percent classified as angular $\left(\mathrm{S}_{\mathrm{i}}>0.6\right)$ correctly ranks the sands in order of known performance (see table 3).

During the development of the Shape Index, it was observed that long rod-like shapes gave the highest values. The Shape Index gives the highest score to objects that have the highest percentage of their perimeters concentrated in long straight lines, usually square, diamond, or triangular in shape. However, a rod shape is the extreme example with almost all of the perimeter concentrated into two straight lines. Since, rod-like particles are not considered angular, the name Angularity was not given to this index. In contrast, the Roundness Index is very low for rod shaped objects, since the straight line segments lie close to the center of the object and not at the periphery. The Shape Index would be a 
good predictor of angularity if rod shaped particles were excluded by low values of the Roundness Index.

The combination of the Roundness Index and the Shape Index was not studied. However, it is clear that the two indices measure two different things and the combination of the two indices has more information about particle shape that either taken separately. Using the two indices in combination will require further study.

\section{Summary}

- A computer controlled sample transport system was developed. A $150 \mathrm{~mm}$ by 150 $\mathrm{mm}$ area is available for sample presentation to the imaging system with either top or bottom illumination of the sample. Sample movement is smooth and fast with enough spatial resolution for viewing material under high magnification.

- The capability of accurately digitizing the images of $0.3 \mathrm{~mm}$ material ( +50 sieve) and larger was demonstrated. Higher magnification should be achievable with microscope objectives.

- Software was developed that can identify and separate objects and then extract the edge trace of each object in the field of view. Data from multiple images are written to a file for latter analysis.

- Software was developed that corrected for the video systems' aspect ratio, then extracted perimeter, area, width, length, maximum length, and aspect ratio for each object stored in the data base.

- Four indices of shape were developed and studied. The Roundness Index accurately identified round (spherical) particles and the Shape Index accurately distinguished angular particles. The Shape Index correlated well with the known performance of selected sands.

\section{Recommendations}

- A much larger selection of aggregate, not just limited to sands, should be studied to determine the usefulness of the Roundness Index and the Shape Index as a predictor of performance. Further research should: 1) quantitatively determine the relative importance of the shape of fine and coarse aggregate in mix design, and 2) quantitatively predict the performance of mixtures (manufactured sand mixed with natural sand).

- A computer model, based on the concepts of finite element analysis, should be developed to utilized the captured images of aggregate in order to explore particle-toparticle forces. Such a model may be able to determine optimum gradation given a measured distribution of shapes. 



\section{APPENDIX A: FILE PROTOCOL}

To facilitate the collection and analysis of aggregated data, a standard file format is herein defined. The data collection system is of two parts: 1) data capture and 2) data analysis. The data capture system captures a video image, identifies all objects (even if incomplete), and writes the data to the hard disk. Two files will be written by the data capture program: the vector trace (the X, Y coordinates of each edge pixel of each object) and the metadata for each data set.

The following rules are to guide the software development:

1. The two files are named FILENAME.VEC (for the vector trace data file) and FILENAME.MET (for the metadata file). The filename is used to identify data sets, however, this information is also included in the metadata file.

2. The vector trace file includes the position of the $X Y$ table, frame delimiters, and vector data for each object. It is the responsibility of the analysis program(s) to detect an incomplete object, edge touching object, and to verify data integrity.

3. The data capture program will not analyze the data. This will be done off line by the analysis program(s).

4. The metadata file includes the sample name, the calibration factors, the lens data, and anything relevant to the data that the technician wishes to include.

5. All output files are to be ASCII text files.

6. The data capture program will get the $X Y$ stage movement instructions from the XYMOVE.DAT file and the calibration data from the CAL.DAT file. The CAL.DAT file will be written to the first line in the FILENAME.MET file.

FILENAME.VEC Specifications follow:

-2 -2 "Velmex movement string" ;first position of XY table, starting from home

$\mathrm{x} 1 \mathrm{yl} \quad$;first data point, first object, first frame

$\mathrm{x} 2 \mathrm{y} 2$

$\mathrm{x} 3 \mathrm{y} 3$

$\mathrm{x} 4 \mathrm{y} 4$

$-1-1$

$\mathrm{x} 1 \mathrm{y} 1$

$\mathrm{x} 2 \mathrm{y} 2$

$\mathrm{x} 3 \mathrm{y} 3$

$-1-1$

$-2-2$ "Velmex movement string" ;end of first frame

$\mathrm{xl} y \mathrm{y} \quad$;irst data point, first object, second frame

$\mathrm{x} 2 \mathrm{y} 2$

$\mathrm{x} 3 \mathrm{y} 3$

$\mathrm{x} 4 \mathrm{y} 4$

$-1-1$ 
x1 y1 ;first data point, second object, second frame

$\mathrm{x} 2 \mathrm{y} 2$

$\mathrm{x} 3 \mathrm{y} 3$

$\mathrm{x} 4 \mathrm{y} 4$

$-1-1$

$-3-3 \quad$;end of data file

FILENAME.MET specifications follow:

Xscale Yscale ; Center-to-center spacing of the pixels in millimeters, (floating point)

String data follows:

1. FILENAME

2. Date

3. Time

4. Sample Name

5. Optics and image distance

6. Special remarks 


\section{REFERENCES}

1. R. R. Lottman and W. H. Goetz, "Effect of Crushed Gravel Fine Aggregate on the Strength of Asphaltic Surface Mixtures" National Sand Gravel Association Circular No. 63, 1956.

2. E. Shklarsky and M. Livneh, "The Use of Gravels for Bituminous Paving Mixtures", Proc. AAPT, Vol. 33, 1964.

3. P. S. Kandhal, J. B. Motter and M. A. Khatri, "Evaluation on Particle Shape and Texture: Manufactured versus Natural Sands", Proceedings of the 70th Annual Transportation Research Board Meeting, Jan. 13-17, 1991, Washingtion, DC.

4. M. Herrin and W. H. Gotez, "Effect of Aggregate Shape on the Stability of Bituminous Mixes", Proceedings, Highway Research Board, Vol. 33, 1954, pp. 293308.

5. I. V. Kalcheff, and D. G. Tunnicliff, "Effects of Crushed Stone Aggregate Size and Shape on Properties of Asphalt Concrete", Proceedings, AAPT, Vol. 51, 1982, pp. 453-483.

6. G. Rittenhouse, "The Relation of Shape to the Passing of Grains Through Sieves", Industrial Engineering Chem. Anal., Vol. 15, No. 2, 1943, pp. 153-155.

7. K. D. Stuart and W. S. Mogawer, "Evaluation Of Natural Sands Used In Asphalt Mixtures", Technical Report No. FHWA-RD-93-070, Federal Highway Administration, 6300 Georgetown Pike, McLean, VA, 1993.

8. G. R. Laughlin, "Limestone Fine Aggregate in Portland Cement Concrete", Highway Research Laboratory, Lexington, KY, 1960.

9. R. D. Barksdale, M. A. Kemp, W. J. Sheffield and J. L. Hubbard, "Measurement of Aggregate Shape, Surface Area and Roughness", Transportation Research Record, Record No. 1301, pp. 107-116, 1991.

10. L. Li, P. Chan, D. G. Zollinger, and R. L. Lytton, "Quantitative Analysis of Aggregate Based on Fractals", Proceedings of the 72nd Annual Transportation Research Board Meeting, Jan. 10-14, 1993, Washington DC.

11. J. W. Landis, "Aggregate Analysis Using Image Processing", Masters Thesis, Univ. of Ark. at Little Rock, May, 1991.

12. C. R. Tamanaha, "Image Processing Instrumentation For Giardia Lamblia Cyst Identification and Enumeration", Masters Thesis, Univ. of Ark., Fayetteville, May 1990.

13. W. K. Pratt, "Digital Image Processing", second edition, John Wiley \& Sons, Inc., 1991, pp. 613-622. 
